\title{
Corneal Micropigmentation
}

\author{
Charles S Zwerling* \\ Department of Ophthalmology, Medical Office Place, USA
}

Submission: February 28, 2018; Published: April 25, 2018

"Corresponding author: Charles S Zwerling, Department of Ophthalmology, Medical Office Place, USA, Tel: 919-736-3937, Fax: 919-735-3701, Email: zwerling@ballroom.org

\begin{abstract}
Corneal micro pigmentation is an alternative surgical treatment to enucleation in blind formed eyes. Micro pigmentation is a form of tattooing in which minute, metabolically inert pigment granules are placed mechanically or manually below the epidermis for the purpose of caosmetic and/or corrective enhancement. Micro pigmentation is also known as permanent makeup, cosmetic tattooing and differs from classic tattooing in which indelible pigments are implanted intradermally and/or the skin is scarred to create legends, decorative art and/or symbolism for the purpose of body adornment. Recently, there has been a renewed interest in mechanical pigmentation of the cornea as a surgical option to enucleation and treatment of unstable corneal surfaces in patients with blind eyes.
\end{abstract}

Keywords: Cornea; Micropigmentation; Tattooing; Enuculeation; Pigments; Recurrent cornea erosion; Leucomata

\section{Introduction}

The early evidence of tattooing can be traced back to the Ice Age or 8,000 BC. Egyptian mummies display tattoos on women from about 4,000 years ago. Tattooing continues to be present in numerous cultures as an expression of body decoration. Micropigmentation is a form of tattooing in which minute, metabolically inert pigment granules are placed mechanically or manually below the epidermis for the purpose of cosmetic and/ or corrective enhancement. Micropigmenation is also known as permanent makeup, cosmetic tattooing and differs from classic tattooing which implants indelible pigments intradermally and/or scarification of the skin to create legends, decorative art and/or symbolism for the purpose of body adornment. Micropigmentation was developed as a form of tattooing in the early1980s to augment eyelashes in women with alopecia. Today the use of micropigmentation has greatly expanded to include cosmetic enhancement of numerous areas of the body as well as an alternative to surgical reconstruction (Figure 1).

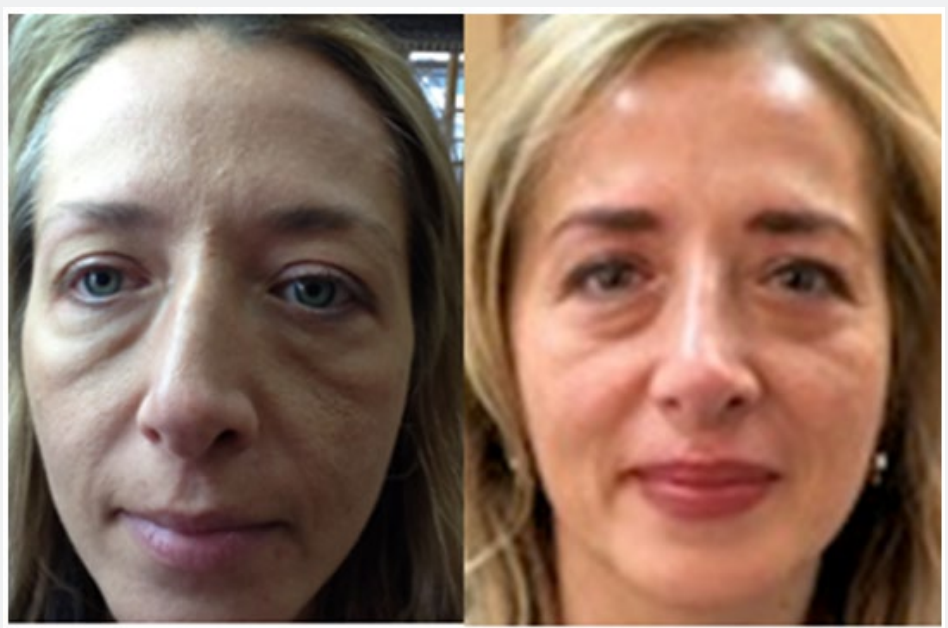

Figure 1: Before and after photos of a typical case of micropigmentation for cosmetic enhancement of brows, eyeliner and lips; courtesy of Hiyan Bitar, DC Permanent Cosmetic Institute (Photo 1 \& 2).

Corneal tattooing is an ancient procedure first ascribed to Galen, a famous physician of the 2nd Century [1,2]. To camouflage unsightly leucomata, Galen used a chemical method to color the cornea, a method involving the precipitation of a pigment in the corneal tissue [3]. Another coloring method of introducing pigments into the corneal tissue was first recorded in 1870, when von Wecker injected India ink into a scarred cornea [4]. This method was not widely adopted due to tissue irritation, fading of the color and other complications including inflammation, ulceration and infection [5]. 
In 1925, Knapp attempted to revive the Galen method using a solution of gold chloride reduced with adrenaline or tannic acid [6]. However, the procedure was deemed dangerous following reports of severe reactions. For this reason, as well as disappointing results, the popularity of the procedure waned [7].

In the following decades, the development of colored contact lenses and prosthetic devices made the tattoo procedure almost unnecessary. However, in the last decade, it became clear that not all patients can tolerate contact lenses and many refuse to undergo the disfigurement and pain of an enucleation or evisceration order to be fitted with a prosthetic eye [8]. Once again, physicians began treating their patients with various tattoo procedures and products [9].

To date, there is no optimal method of a surgical technique for corneal micropigmentation [10]. Some physicians mix their own tattoo pigments with saline or alcohol [11] while other practitioners use commercially available non-sterile pigments and sterilize it by autoclave [8]. Some physicians use hand held needles to inject the pigment [11] whereas, others use a mechanized instrument [14]. This paper presents a case of corneal micropigmentation using a modern reciprocating, medical grade machine with commercially available, sterile, premixed pigments [9].

\section{Materials and Methods}

The patient is a 58-year-old African-american male who years earlier sustained a severe alkali chemical burn to his right eye. This injury caused continued episodes of re-inflammation of the right eye, symblepheron formation, and recurrent corneal erosions. The patient most recently had corneal neovascular changes as a result of chronic corneal erosions related to instability of the corneal surface. He elected to undergo corneal micropigmentation of the right eye in order to improve the ocular surface as well as provide cosmetic relief. The patient understood, however, that if the corneal tissue was not viable and he sustained loss of anterior chamber contents as a result of the corneal punctures and micropigmentation, he would have to undergo immediate evisceration of the right eye.

The patient was taken to the main operating room at Wayne Memorial Hospital where he was prepped in the usual manner for intraocular surgery. The patient was draped in a sterile fashion giving exposure to his right eye. Anesthesia and akinesia were obtained by means of general endotracheal anesthetics. Jaffe lid retractors were placed into the patient's right eye and using calipers, the optical center of the right eye was determined to be at $6 \mathrm{~mm}$ (Figure 2).
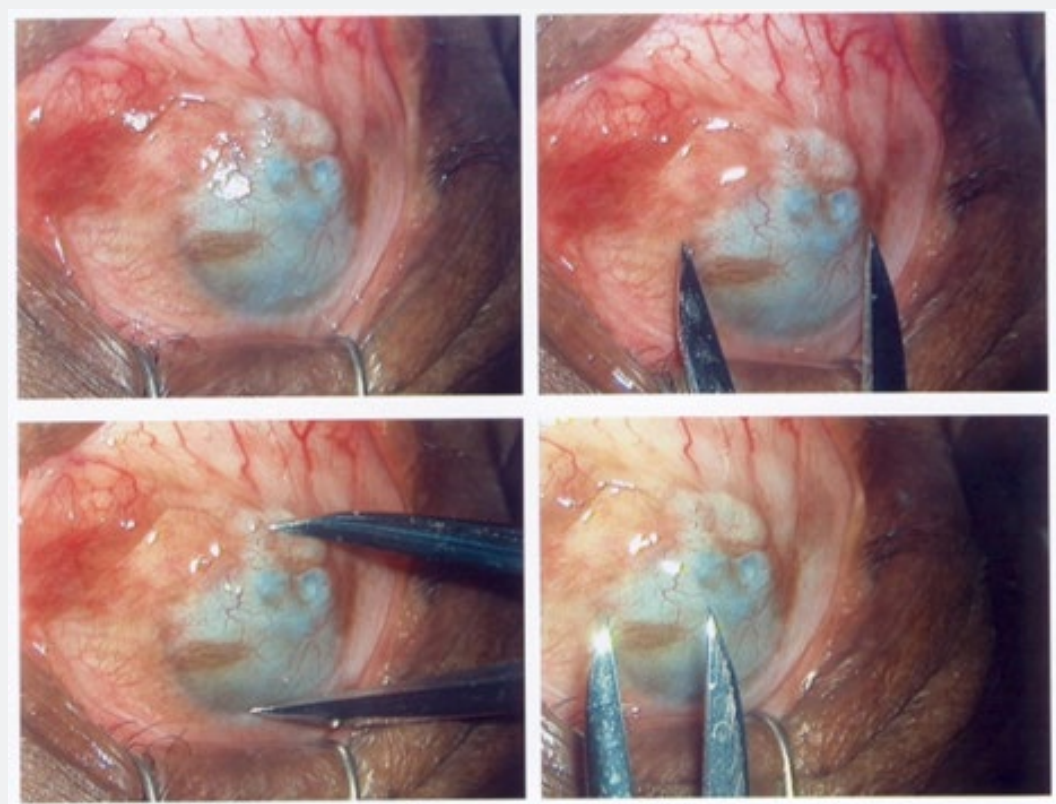

WAYNE NEMORIAL HOSPITAL

Figure 2: Pre-operative photo demonstrating damaged right eye and use of calipers to determine optical center for placement of the pupil (Photo 3).

This area was carefully marked with black pigment (Permark®, Permark Inc, Edison, NJ) on a cotton tip applicator. Then, using a No. 9 needle cluster attached to a reciprocating, micropigmentation machine (Permark $®$, Permark Inc, Edison, NJ), an artificial pupil was created at the optical center of the cornea.

The size of this pupil, between 3-4 $\mathrm{mm}$ in diameter, was determined by the contra-lateral eye (Figure 3). Switching to a dark brown pigment (Permark®, Permark Inc, Edison, NJ) and using 0.12 forceps to stabilize the eye, radial pigmentation was performed in a 360 degree surface. The needle excursion varied between $1.00 \mathrm{~mm}$ and $1.25 \mathrm{~mm}$ at an angle of 45 degrees. In this way, depth into the cornea matrix was controlled and allowed the pigment to be deposited into the stromal layers. Special attention was applied to the cystic corneal bleb that was located inferior/ temporally in the mid corneal region. This area was carefully pigmented to avoid corneal perforation (Figure 4). 


\section{Annals of Reviews and Research}
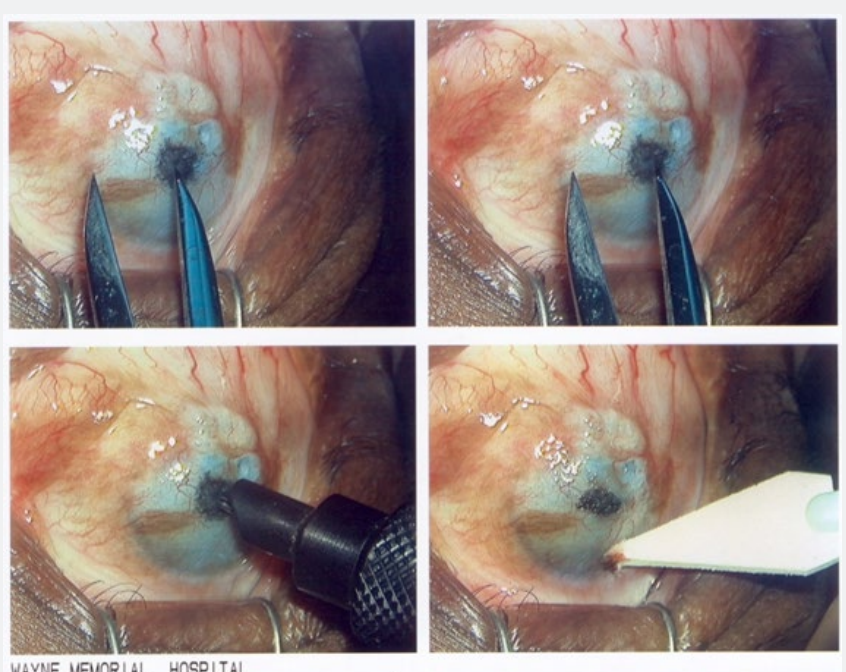

Figure 3: Calipers confirm central placement of pigmentation to create artificial pupil (Photo 4).
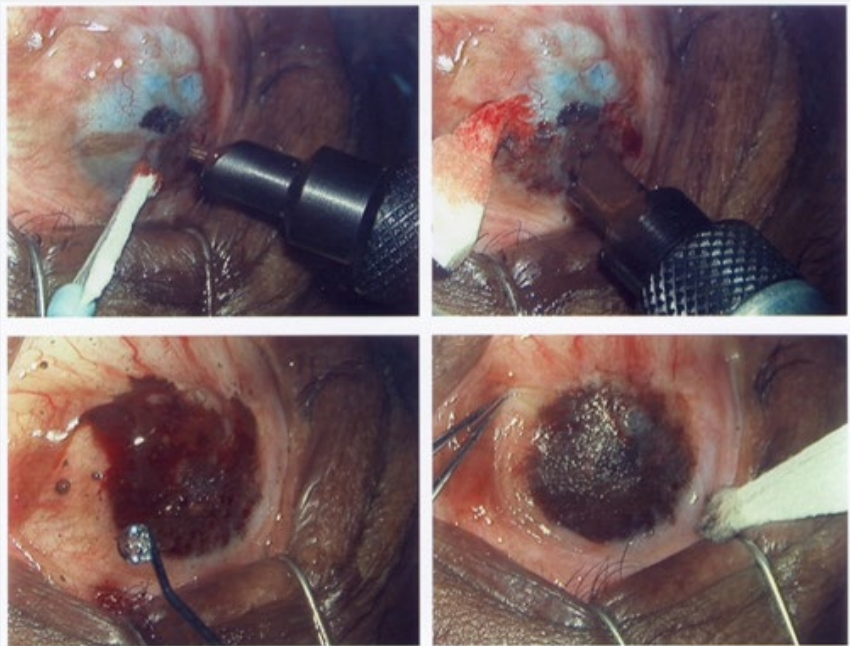

WAYNE NENORIAL HOSPITAL

Figure 4: The area of cornea was checked for symmetry and color and additional areas of radial artificial iris was enhanced by means of the black pigment (Photo 5).
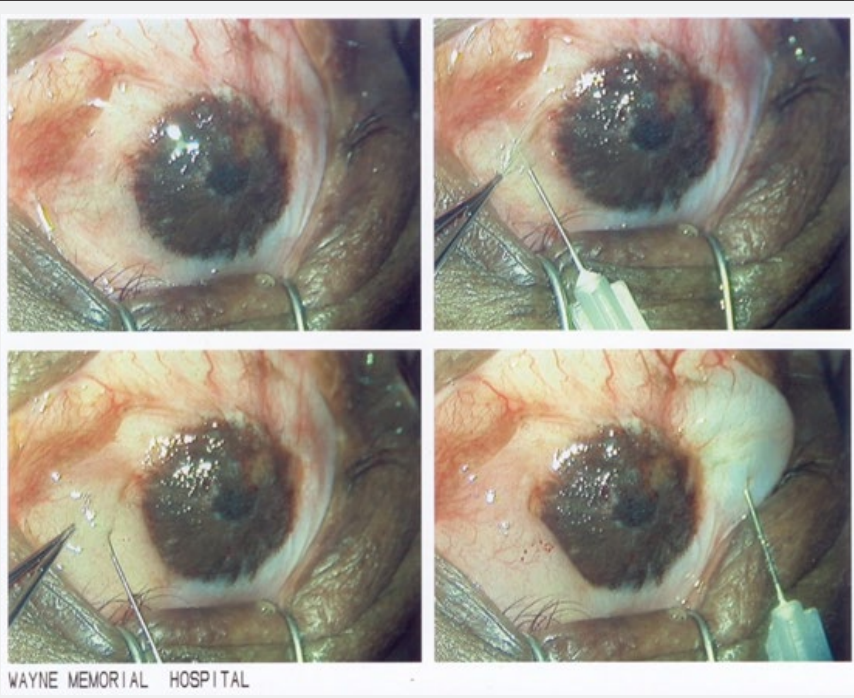

Figure 5: At the conclusion of the case, $20 \mathrm{mg}$ of Solu-Medrol and $20 \mathrm{mg}$ of Garamycin and $3 \mathrm{cc}$ of Xylocaine \% solution were all injected subconjunctivally (Photo 6). 
The pigmentation treatment created a pleasing effect to the right eye as well as stabilizing the corneal surface. Hemostasis from bleeding of the corneal neovascularization was achieved by means of topical pressure, using a Weckcel sponge, soaked in balanced salt solution with topical 4\% Cocaine solution (Figure $5)$.

The eye was then pressure patched with TobraDex ophthalmic ointment (Alcon Laboratories, Inc., Fort Worth, TX) and an ice packed placed over the right eye. The patient tolerated the procedure well and left the operating room in excellent condition.

\section{Result}

Following surgery the patient was very pleased with the cosmetic enhancement. Moreover, the patient noticed a significant reduction in corneal pain for the first time in years. The patient was examined 24 hours later and was dispensed Tobra Dex ophthalmic solution (2 drops to the operated eye 4 times per day) and TobraDex ophthalmic ointment $1 / 4$ (apply to the operated eye at bedtime). The corneal tattoo was well placed and symmetrical with the patient's contra-lateral eye. The color match was excellent. Inflammation was $+1 /+2$ of the conjunctival and limbal vessels. The patient was seen one week later with virtually no inflammation noted. There was some mild loss of superficial tattoo pigment from sloughing of the corneal epithelium.

One month postoperatively, the operated eye was completely quiet with no signs of any corneal erosions or irritation. The corneal epithelium had become more resistant to recurrent corneal erosions as a result of the micropigmentation and subsequent healing process. The treated eye has remained quiet and retains the color from the micropigmentation treatment.

\section{Discussion}

Micropigmentation of the cornea can be performed by a variety of methods including the hand method (hand-held needles) [15], rotary machines, and/or reciprocating tattoo machines. The hand method has been reported to result in irregular pigment deposition and early fading [16]. The machine method has previously been reported to be superior in that it can achieve many more penetrations per second with a uniform force and depth. The choice of machine is usually the result of personal preference. However, from the standpoint of depth of penetration and safety, a reciprocating medical grade micropigmentation machine was selected, since it was engineered for precision and meets OSHA and Operating Room specifications.

A variety of substances have been used for corneal micropigmentation including India ink, lamp black, organic dyes and chemically reduced metallic salts. It is well documented in the medical literature that many of these colorants have created new inflammatory problems for the patient. Pigments made with talc were reported to produce unacceptable granulomas. Other complications included discoloration ranging from mild fading to total loss of color. Common tattoo pigments have been found to cause irritations or inflammatory reactions in the skin and may do the same when used in the more sensitive tissues of the eye. K.L.Pickrell had good success and no complications when he used dry pigments which were autoclaved and mixed with saline.

The iron oxide based pigments used in this case are premixed from FD\&C approved ingredients and sold sterile. The most common complications of corneal micropigmentation have been ocular discomfort, conjuntival injection and mild keratitis. However, corneal ulceration, iridocyclitis, and panophthalmitis have also been reported. The contraindications include but are not limited to, adherent leucoma, keratectasia, anterior staphyloma, neurotrophic keratopathy, phthisis bulbi and glaucomatous eyes.

\section{Conclusion}

Corneal tattooing has been discussed sporadically in the medical literature in the past 134 years; however, there has been recently a resurgence of interest in corneal tattooing or micropigmentation as a surgical option for unstable corneal surfaces in patients with blind eyes. Most patients would prefer keeping their own eyes versus the use of an artificial eye. Moreover, the surgical risks of evisceration or enucleation are significant when compared to corneal micropigmentation. The benefit of corneal puncture in the treatment of recurrent corneal erosions is well documented in the medical literature as well.

Thus, corneal micropigmentation represents an alternative surgical treatment to enucleation in blind deformed eyes. This surgical procedure offers an enhanced cosmetic appearance as well as potential stabilization of corneal surfaces for certain patients.

\section{References}

1. Anastas CN, McGhee CN, Webber SK, Bryce IG (1995) Corneal tattooing revisited: excimer laser in the treatment of unsightly leucomata. Aust NZ J Ophthalmol 23(3): 227-230.

2. Ziegler SL (1922) Multicolor tattooing of the cornea. Transactions of the American Ophthalmological Society 20: 71-87.

3. Pickrell KL, Edwards BF, Broadbent TR, Wilde NJ, Metzger JT (1951) Corneal Tattoo for restoration of eye color, Plast Reconstr Surg 7(4): 263-270.

4. Wessels IF, Wessels GF (1996) Mechanized Keratomicropigmentation: Corneal Tattooing with the Blepharopigmentor. Opthalmic Surg Lasers 27(1): 25-28.

5. Velpandian (2016) Pharmacology of Ocular Therapeutics. pp. 431.

6. Pitz S, Jahn R, Frisch L, Duis A, Pfeiffer N (2002) Corneal Tattooing: an alternative treatment for disfiguring corneal scars, Br J Ophthalmol 86(4): 397-399.

7. Zwerling CS, Christensen FF, Goldstein NF (1986) Micropigmentation.

8. Panda A, Pangtey MS, Sony P (2002) Corneal Tattooing. Br J Ophthalmology 86(12): 1461. 
9. Velden EM, Samderubun, Kok JH (1994) Dermatography as a Modern treatment for coloring Leucoma Corneae, Cornea 13(4): 349-353.

10. Zwerling CS, Walker, Annette, Goldstein NF (1993) Micropigmentation: State of the Art. Alfaretta Georgia: Apex Book Manufacturing.

11. Vassileva S, Hristakieva E (2007) Medical Applications of Tattooing. Clinics in Dermatology 25(4): 367-374.

12. Burris TE, Holmes-Higgin DK, Silvestrini TA (1998) Lamellar intrastromal corneal tattoo for treating iris defects (artificial iris). Cornea 17(2): 173.
13. H den Dulk (1995) Corneal Tattooing. Cornea 14(2): 225.

14. Angres Giora (1986) Surgical maneuvers: Eyelid pigmentation technique and pretreatment patient considerations. Ocul Surgery News 4: 22.

15.Zwerling CS, Dixon LH, Christensen FF, Goldstein NF (2010) Micropigmentation Millennium, Alfaretta Georgia: Apex Book Manufacturing.

16. Corneal Tattoo Case-personal communication submitted by Heid Lassiter, RN, DAAM, Professional Dermagraphics Permanent Make-up in Raleigh.

\section{Your next submission with Juniper Publishers will reach you the below assets}

- Quality Editorial service

- Swift Peer Review

- Reprints availability

- E-prints Service

- Manuscript Podcast for convenient understanding

- Global attainment for your research

- Manuscript accessibility in different formats

( Pdf, E-pub, Full Text, Audio)

- Unceasing customer service

Track the below URL for one-step submission https://juniperpublishers.com/online-submission.php 